\title{
Attendance of Tunisian Supermarkets and Hypermarkets
}

\author{
Basma Amamou Yaich \\ Departement of Management/ HITS Bizerte, Tunisia
}

\begin{abstract}
In this research, we examined the relationship between determinants of satisfaction (environmental factors, price, utilitarian criteria, factors of atmosphere and peripheral services) and satisfaction, on one hand, and the relation between satisfaction, access and the level of attendance on the other hand. So, we used in this research, simple linear regression and logistics regression. We chose conveniently, the customers of Tunisian supermarkets and hypermarkets to answer our quiz.
\end{abstract}

Keywords - access, level of supermarkets and hypermarkets's attendance, logistic, regressions, satisfaction

\section{INTRODUCTION}

In Tunisia, the researches on attendance supermarkets and hypermarkets (supermarkets and hypermarkets) are not wide spread as expected with the varied field distribution as we can see in the study by M. Debabi [1]. This development is reflected by: (1) the expansion of Tunisian supermarkets and hypermarkets' sales, (2) the agreements between Tunisian distributors (supermarkets and hypermarkets) and foreign partners, and (3) the opening of two hypermarkets. The goal of the distributors is to ensure regular attendance of their supermarkets and hypermarkets.

Many researchers have analyzed the selected criteria and attendance of supermarkets and hypermarkets [2;3]. According to those authors, one of these criteria is satisfaction.

Our problematic was to find the impact of environmental factors, price, utilitarian criteria, factors of atmosphere and peripheral services on satisfaction and the impact of satisfaction and access on the level of attendance. So, we proceed to classify these determinants according to the importance of their impact.

\section{BeHAVIOR OF SUPERMARKETS AND HYPERMARKETS' ATtENDANCE}

To emphasize attendance at supermarkets and hypermarkets, we must implement the marketing actions to attendance. The marketing actions affect the customer behavioral variables, including those that determine its attendance at supermarkets and hypermarkets.

Many of attendance variables of supermarkets and hypermarkets are: price, assortment, service to customers, promotions, availability of brands and desired products, merchandising technics, and finally the atmosphere.

To choose one among several competing supermarkets and hypermarkets, the customer depends on the factors. - Physical factors: Some authors have identified the two physical variables: the size of the mall and its distance from the home or travel during from the mall to home [4]. D. Rulence considers that the increase of the supermarkets and hypermarkets surface increases their attractivity [5]. The retailer seeks to increase the supermarkets and hypermarkets surface in a given territory increasingly large, constantly conquer new markets and customers.

- Business factors: Y. Negro identified the following criteria: packaging, display window, staff amiability, service, speed purchase, assortment, interior arrangement, notoriety and price [6].

- Additional services: Some authors have assessed "the factors that increase for customers, the commercial value of malls they frequent: the supply of services based on customer expectations, by supplying additional services around the basic services forming the so-called "commercial services" [7].

- Other authors have announced five criteria affecting attendance at supermarkets and hypermarkets: price, sellers tips, post-purchase safety, convenience - proximity and range of choice [8].

In fact, we can distinguish in this section, the determinants of satisfaction (environmental factors, attributes of price, utilitarian criteria, factors of atmosphere and peripheral services), as well as the determinants of attendance (satisfaction and access).

\section{The attributes related to the environment}

They are particularly associated with satisfaction such as [3]:

- Amiability is essential;

- The prestige, the quality of public spaces, architecture and familiarity of the customer with supermarkets and hypermarkets are key criteria to satisfaction.

- The safety of the vehicle in the parking and the quality of attendance are key criteria of second row.

- The general safety, the ease to recognize and move, and the animation during the day are required to satisfy. 
- The evening animation increases satisfaction when it is well viewed (criteria "more").

Environmental attributes are considered generally better for customers, except safety criterion. In addition, a misregistration causes dissatisfaction. They consist of those criteria: friends, familiar, prestige, reception, decor, reference, security, animation, and attendance, secure parking, evening.

\section{The attributes of price}

In terms of prices, the impact on satisfaction differs according to attributes [3]. The price is represented by good business, on sale, prices, promotion.

- Supermarkets and hypermarkets often practice attractive prices and supply a wide range of prices for substitute products.

- The perspective of good business is the most significant (first row key criterion).

- Practices on sale plays less roll and influence low satisfaction (secondary criteran).

- The frequency of promotions or honesty of price influence less satisfaction. The promotion is widely used to increase the attractiveness [9]. The supermarkets and hypermarkets dictate to providers the duty to prepare an annual program of promotional activity.

\section{The utilitarian criteria}

Some authors have confirmed that the criteria affecting satisfaction and thereafter attendance of supermarkets and hypermarkets are classified "basic", "more" and "secondary" [10].

- "Basic" criterion is the object of supermarkets and hypermarkets distribution service. They recall the traditional supermarkets. They are essentially utilitarian criteria. The contribution of criteria "basic" is low level of satisfaction when they are viewed positively by customers and strong when they are viewed negatively by customers. That is to say that if a basic criterion is evaluated negatively by the customers, it contributes significantly to the level of overall satisfaction.

- Criterion "more" creates a state of "enchantment" [11]. Criterion "more" contains several peripheral services and three utilitarian criteria [2]. Distributors shall act on these criteria to differentiate their supply. The contribution of criteria "more" is high level of satisfaction when they are viewed positively by customers and low when they are viewed negatively by customers.

- Criteria "secondary" contain several peripheral services [2]. They have no roll in overall satisfaction. These are considered as tools loyalty. The contribution of "secondary" criteria is low level of satisfaction when they are viewed positively or negatively by customers.

The following table presents a summary of the "basic", "key", "more" and as secondary criteria affecting satisfaction. These criteria have been confirmed in the field of restoration and bank [12] and then in the supermarkets and hypermarkets [2].

\begin{tabular}{|l|l|l|l|}
\hline Criteria & \multicolumn{1}{|c|}{ Utilitarian criteria } & \multicolumn{1}{c|}{ Atmosphere factors } & \multicolumn{1}{c|}{ Peripheral services } \\
\hline Basic & $\begin{array}{l}\text { Fair price, product selection, } \\
\text { Q / P, easy to find, tidy }\end{array}$ & Cleanliness, temperature & \\
\hline Key & $\begin{array}{l}\text { Available, information, } \\
\text { signaling }\end{array}$ & $\begin{array}{l}\text { Frame interior, exterior, } \\
\text { Smells, colors, waiting }\end{array}$ & \\
\hline More & Origin, promotion, lot & music & $\begin{array}{l}\text { After-sales services, } \\
\text { services, child, gift wrap }\end{array}$ \\
\hline Secondary & Access, accessible & $\begin{array}{l}\text { Animation, number, gallery } \\
\text { staff }\end{array}$ & $\begin{array}{l}\text { Bag, gift, distributor, } \\
\text { schedules }\end{array}$ \\
\hline
\end{tabular}

The contribution of following utilitarian criteria (fair price, product selection, Q / P, easy to find, tidy) is low level of satisfaction when they are viewed positively by customers and strong when they are viewed negatively by customers.

The contribution of following utilitarian criteria (the logical layout of rays, information and signaling on the product) is strong at the level of satisfaction when they are viewed positively or negatively by customers.

The contribution of following utilitarian criteria (products origin, promotions and lot size) is strong at level of satisfaction when they are viewed positively by customers and low when they are viewed negatively by customers.

The utilitarian criteria, in their majority, have a fluctuating weight on customer satisfaction.

\section{Peripheral criteria}

The contribution of following peripheral criteria (after-sales services, services in the shelves, children's activities, gift wrap) is high at level of satisfaction when they are viewed positively by customers and low when they are viewed negatively by customers [2]. 
The contribution of following peripheral criteria (bag, gift, distributor, access times) is low at level of satisfaction when they are viewed positively or negatively by customers.

Peripheral criteria have essentially contributed to customer satisfaction.

\section{The atmosphere factors}

The contribution of atmosphere factors (frame inside, outside, smells, colors, waiting) is high at level of satisfaction when they are viewed positively or negatively by customers [2].

The contribution of atmosphere factors (cleanliness, temperature) is low at level of satisfaction when they are viewed positively by customers and strong when they are viewed negatively by customers.

The contribution of atmosphere factors (animation, number, gallery and staff) is low at level of satisfaction when they are viewed positively or negatively by customers.

\section{The satisfaction}

After purchasing and using the product, the customer will experience a feeling post-purchase: either satisfaction or dissatisfaction. The satisfaction belongs to the process following purchase. Other authors have defined satisfaction as the extent of what the customers feels subjectively pleased with the ownership and use of products [13].PY. Leo and J. Philippe [3] obtained the following two results: the satisfaction toward a supermarkets and hypermarkets has a decisive influence on the attendance of supermarkets and hypermarkets ; the opinion of customer on supermarkets and hypermarkets can be measured by a satisfaction multi-items scale agreed in that a single measurement consists of: intention, recommendation, satisfaction, comparing, repetition and pleasure.

\section{Access}

PY. Leo and J. Philippe found that the attractiveness of supermarkets and hypermarkets depends on access to the supermarkets and hypermarkets [3]. Accessibility is the advantage of supermarkets and hypermarkets in outskirts in terms of ease of traffic and parking. Security access path is important to the city center but secondary on the outskirts. Accessibility is sought through these criteria: location, safe trip, trip, people, parking. Explaining the level of attendance by a supermarkets and hypermarkets customer, P.Y. Leo and J. Philippe indicated that the distance at which the customer is located is a key criterion. But the satisfaction indicator is not correlated with distance [3]. Accessibility is sought through these criteria: location, safe trip, trip, crowds, parking.

\section{The level of attendance of supermarkets and hypermarkets}

Leo, PY and Philippe J showed three categories of attendance: episodic attendance (four times a year or less often), a sustained attendance (at least once a week) and regular attendance (monthly or multi month) [3].

These authors modeled successively the two extreme attendances, which showed two major types of determinant criteria at the level of attendance in supermarkets and hypermarkets by a customer:

- Access (distance-time and the possession of a car);

- Satisfaction issued from the supermarkets and hypermarkets plays an intermediary roll between its determinants and the level of attendance.

The level of attendance contains a single item that is: what is the level of your average attendance of your main supermarket/hypermarket? [3].

As some authors have said, satisfaction is a factor in attendance of supermarkets and hypermarkets and determined by the environmental attributes, price, peripheral services, utilitarian criteria and the atmosphere while attendance is determined by the satisfaction and access [3].

\section{THE PRESENTATION OF THE CONCEPTUAL MODEL}

In this section, we present our research hypotheses, our conceptual model and measurement of variables.

1.The presentation of the research hypotheses

1.1. The effect of the environment supplied by the supermarkets and hypermarkets on the satisfaction

Attributes related to the environment are closely related to satisfaction [3].

Among the environmental factors supplied by the supermarkets and hypermarkets, we find tow items: free parking and architecture that have a positive impact on customer satisfaction [14].

The environment consists of the following 12 items:

\begin{tabular}{|l|}
\hline "You can meet friends with pleasure" \\
\hline "We are easily identified" \\
\hline "This is a place that has some prestige" \\
\hline "The public spaces are welcoming" \\
\hline
\end{tabular}




\begin{tabular}{|l|}
\hline "I feel comfortable, like at home" \\
\hline "There are a lot of supermarkets and hypermarkets that interest me" \\
\hline "The architecture is interesting" \\
\hline "We feel very safe in this supermarkets and hypermarkets" \\
\hline "We don't make a bad encounter" \\
\hline "It is an animated place in the day" \\
\hline "My car occurs no risk" \\
\hline "It is an animated place even late at night" \\
\hline
\end{tabular}

We set hypothesis 1: The environment supplied by the supermarkets and hypermarkets has a positive impact on satisfaction.

1.2. The effect of price on satisfaction

The contribution of the price is high at level of satisfaction when it is viewed negatively by customers [2].

Price factors are the following four items:

\begin{tabular}{|l|}
\hline "It makes good business" \\
\hline "The prices are generally honest" \\
\hline "There is always something on sale or promotion" \\
\hline "The sales are interesting" \\
\hline
\end{tabular}

We set hypothesis 2: The price has a positive impact on satisfaction.

1.3. The effect of utilitarian criteria on satisfaction

The utilitarian criteria have, in majority, a fluctuating weight on satisfaction [2].

Among utilitarian criteria we find the information on products that have a positive impact on customer's satisfaction [14].

The utilitarian criteria consist of the following eight items [2]:

\begin{tabular}{|l|}
\hline "The quality/price ratio was good" \\
\hline "The supermarkets and hypermarkets was tidy" \\
\hline "The arrangement of shelves seemed logical to you" \\
\hline "The information on the characteristics of the different products were sufficient" \\
\hline "The shelves were well reported" \\
\hline "The information on the origin of products (and the origin of their components) seemed \\
sufficient to you" \\
\hline "Lots of more products correspond with your expectations (lots 2, 4,6 ...)" \\
\hline "All products were available (placed neither too high nor too low in the raw)" \\
\hline
\end{tabular}

We set hypothesis 3: The utilitarian criteria have a positive impact on satisfaction.

1.4. The effect of peripheral services on satisfaction

Among the peripheral services supplied to customers, we find the following items: after-sales service and the safeguards that have a positive impact on customer satisfaction [14].

Peripheral services have essentially contributed to customer satisfaction.

Peripheral services are the following seven items [2]:

\begin{tabular}{|l|}
\hline "The after-sales service seemed quite sure to you" \\
\hline "Many services were supplied on the raw (possibility to order,...)" \\
\hline "It was pors activities for children (games ...)" \\
\hline "The bags were free" \\
\hline "The supermarkets and hypermarkets supplied gifts or discounts to thank customers for their loyalty" \\
\hline "It was possible to withdraw money from a distributor" \\
\hline
\end{tabular}

We set hypothesis 4: The peripheral services have a positive impact on satisfaction.

1.5. The effect of the atmosphere on satisfaction

Other authors have found that atmosphere factors contribute to satisfaction [2].

Atmosphere variables like the smell, music and colors can enhance the atmosphere of the supermarkets and hypermarkets and cause positive reactions and emotional states among customers [15].

The atmosphere factors are the following nine items: 


\begin{tabular}{|l|}
\hline "The supermarkets and hypermarkets (ground, raw, desk) were clean" \\
\hline "The temperature of the supermarkets and hypermarkets was nice" \\
\hline "The interior was pleasant" \\
\hline "The outside of the supermarkets and hypermarkets (front, sign, landscaping) was pleasant" \\
\hline "The smell in the supermarkets and hypermarkets was pleasant" \\
\hline "The color scheme was nice" \\
\hline "The waiting times were short (to be served, on desk ...)" \\
\hline "There was nice music" \\
\hline "This supermarkets and hypermarkets included a mall" \\
\hline
\end{tabular}

We set hypothesis 5: The atmosphere has a positive impact on satisfaction.

1.6. The effect of satisfaction on the level of attendance

Satisfaction towards supermarkets and hypermarkets has a decisive influence on attendance of supermarkets and hypermarkets. Satisfaction has an impact on loyalty. It is crucial to explain the attendance of supermarkets and hypermarkets [3].

One of the individual or personal criteria of supermarkets and hypermarkets attendance is the pleasure that is one of the items of satisfaction. A social criterion is the pleasure of bargaining [16].

Satisfaction includes the following six items:

\begin{tabular}{|l|}
\hline "Do you intend to continue to attend your main supermarket/hypermarket?"' \\
\hline "You recommend this supermarket/hypermarket to a friend (rather than another)?"' \\
\hline "This supermarket/hypermarket gives overall impression to you ...?' \\
\hline "Compared to another supermarket/hypermarket that you know, it is: ..." \\
\hline "I used to make purchases ..." \\
\hline "It is pleasant to walk in this supermarket/hypermarket?"' \\
\hline
\end{tabular}

1.7. The effect of customer access to the supermarkets and hypermarkets on the level of attendance Explaining the level of supermarket and hypermarket attendance by a customer, the authors stated that the distance at which it is located is an unavoidable factor [3].

Among the factors that could influence the activity of shopping, there are situational and proximity factors [17]. Some authors have identified a physical variable choosing a supermarket/hypermarket: the distance or trip time from the supermarket to home [4].

Access includes the following nine items:

\begin{tabular}{|l|}
\hline "Those supermarkets and hypermarkets were very well located for me" \\
\hline "There is no risk during the trip" \\
\hline "The trip is tiring to come" \\
\hline "You lose a lot of time in the path" \\
\hline "The trip has a cost" \\
\hline "There's often a crowd to enable to move easily" \\
\hline "It is tiring to find a place in parking" \\
\hline "You lose a lot of time to find a place in parking" \\
\hline "The parking has a cost" \\
\hline
\end{tabular}

We set hypothesis 6: The satisfaction and access of customer to the supermarket/hypermarket have a positive impact on the level of attendance.

Hypothesis 6A: Satisfaction has a positive impact on the level of attendance.

Hypothesis 6B: The access of customer to the supermarket/hypermarket has a positive impact on the level of attendance. 
2. The conceptual model

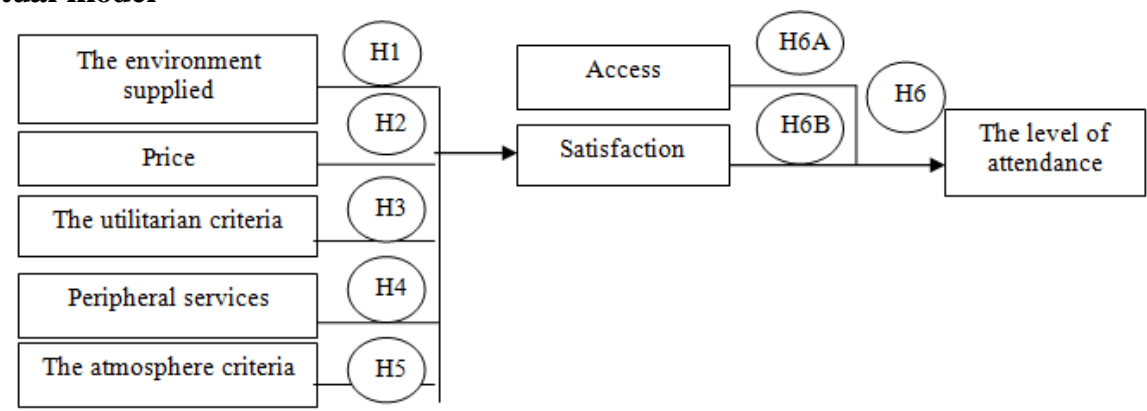

\section{The measurement of variables}

We present in this section the measurement scale used for each variable.

- For the following variables: "the environment supplied by supermarkets", "price", "utilitarian criteria", "peripheral services", the "atmosphere criteria" and "access"; we have used, according to some authors, the same additive scale (Likert) of five levels which measures the "degree of agreement and disagreement" [3].

- For the variable "satisfaction": the multi-item scale of measure of satisfaction toward supermarket and hypermarket is [3]:

For the items "intend", "pleasure" and "repetition", they used an additive scale (Likert) of 5 points.

For the item "satisfaction" they used a categorical verbal scale with seven points.

For the items "recommendation" and "comparing": they used a categorical bipolar scale (semantic differential) of 7 opposite points.

- $\quad$ "The level of supermarkets and hypermarkets attendance" is a variable non metric (ordinal). It is translated by a single choice question [3].

\section{The Presentation Of The Research's Methodology}

We will try in this section to present the method of data collection, the sampling process, the reliability analysis of items of different variables in the model using principal component analysis and analysis methods of data avoked.

\section{The method of data's collection}

The method of data's collection continued in this research is the survey through a quiz. For best quality of answers and to ensure a high enough rate of response, we chose to lead the survey face to face and individually. Thus, we chose to administer quiz to people in the Tunisian supermarkets and hypermarkets chosen arbitrarily ("Carrefour", "Geant", "Carrefour Market", "Monoprix”, "Magasin Général” and "Magro").

\section{The process of sampling}

The population studied is the set of customers over twenty-five years and used to do their shopping in supermarkets. We have customers at random, at the outside of supermarkets and hypermarkets. The size of our convenience sample is equal to 260, about 43 surveyed about for each supermarkets and hypermarkets chosen. We chose every day of the week to reach all customers (50\% of planning is chosen in the middle of the week and the other half is chosen in the weekend).

\section{Purification of measurement's scales: The Principal Component Analysis}

The reliability analysis is done through a Principal Component Analysis (PCA) and the use of the criteria for the implementation of the PCA are:

- The test of Kaiser, Meyer and Olkin (KMO): It shows how all the retained variables are consistent. If the KMO is less than 0.5, it is unacceptable. If the KMO > 0.9 it is satisfying [18].

- Bartlett's test of sphericity checks the hypothesis zero:

With $\mathrm{H}_{0}$ : all correlations are zero. This test can reject the hypothesis zero.

- The restitution of the variance explained by the factors identified is $>0.5 \%$.

- Test reliability: Cronbach Alpha is the indicator of reliability of measurement scales. It measures the internal consistency of the measurement scale multi-items. The coefficient is between 0 and 1 . A scale is reliable if it leads to relatively similar results when measuring the same thing several times [19].

This is a first step in data processing generally recommended by all researchers [8]. The PCA is made for items of each multi-item variable: environment, price, utilitarian criteria, peripheral services, atmosphere, satisfaction and access.

Before using scales of measurement, we must do their purification. We analyze the reliability through the PCA, which is an analysis of the dimensionality of measurement's scale. 
The results of this multi-variable PCA items are:

\subsection{The environment supplied by the supermarkets and hypermarkets}

After a first PCA, we found Cronbach's alpha equal to 0.897 and commonality following eight items below 0.5 (the meeting of friends, ease of identification, the existence of many interesting supermarkets and hypermarkets interesting architecture, bad meeting, animation in the day, no risk for the car and animation in the night).

We repeated the PCA with the four items remaining after the elimination of eight items above. The results of the second PCA were as follows:

\begin{tabular}{|c|c|c|}
\hline Items & Commonality & Component \\
\hline "This is a place that has some prestige" & 0.626 & 0.791 \\
\hline "The public spaces are welcoming" & 0.644 & 0.803 \\
\hline "I feel comfortable, like at home" & 0.736 & 0.858 \\
\hline $\begin{array}{c}\text { "We feel very safe in this supermarkets and } \\
\text { hypermarkets" }\end{array}$ & 0.576 & 0.759 \\
\hline KMO measure of sampling & \multicolumn{2}{l}{0.753} \\
\hline Bartlett's test of sphericity: Chi-square approached & & 670.088 \\
\hline Bartlett's test of sphericity: dll & \multicolumn{2}{c}{} \\
\hline Bartlett's test of sphericity: meaning & & 0 \\
\hline
\end{tabular}

Structure indicators appear acceptable. These items are correlated to the dimension. All these items are factorable to a single factor. This variable is one-dimensional. The environment supplied is represented by four items only. This scale environment supplied by the supermarkets and hypermarkets has a good level of reliability (Cronbach's $\alpha=0.817$ is close to 1$)$ : The scale has good internal consistency. The covariance between the items is high.

\subsection{The price variable}

Following PCA, we found the following indicators for all items of the variable:

\begin{tabular}{|l|l|l|}
\hline Items & Commonality & Component \\
\hline "It makes good business" & 0,580 & 0,761 \\
\hline "The prices are generally honest" & 0,524 & 0,724 \\
\hline "There is always something on sale or promotion" & 0,650 & 0,806 \\
\hline "The on sales are interesting" & 0,646 & 0,804 \\
\hline KMO measure of sampling & & 0,674 \\
\hline Bartlett's test of sphericity: Chi-square approached & & 313,943 \\
\hline Bartlett's test of sphericity: dll & & 6 \\
\hline Bartlett's test of sphericity: meaning & & 0 \\
\hline
\end{tabular}

Structure indicators appear acceptable. We will keep all items in this variable because their communalities are above 0.5 . Contributions are much higher than 0.5. These items are correlated to the dimension. All these items are factorable to a single factor. This variable is one-dimensional.

The scale of the price variable has a good level of reliability (Cronbach's $\alpha=0.937$ is close to 1 ): The scale has good internal consistency. The covariance between the items is high.

\subsection{The variable utilitarian criteria}

After a first PCA, we found Cronbach's alpha equal to 0.812 and the commonality of the four following items below 0.5 (the quality/price ratio, the origin of products, lots of products and accessibility products).

We repeated the PCA with the four items remaining after the removal of the four previous items. The results of the second PCA were as follows:

\begin{tabular}{|l|l|l|}
\hline Items & Commonality & Component \\
\hline "The supermarket / hypermarket was tidy" & 0,52 & 0,721 \\
\hline "The arrangement of shelves seemed logical to you" & 0,671 & 0,819 \\
\hline $\begin{array}{l}\text { "The information on the characteristics of the various } \\
\text { products were sufficient" }\end{array}$ & 0,705 & 0,84 \\
\hline "The raws were well reported" & 0,628 & 0,793 \\
\hline KMO measure of sampling & & 0,762 \\
\hline Bartlett's test of sphericity: Chi-square approached & & 336,309 \\
\hline Bartlett's test of sphericity: dll & & 6 \\
\hline Bartlett's test of sphericity: meaning & & 0 \\
\hline
\end{tabular}


Structure indicators appear acceptable. These items are correlated to the dimension. All these items are factorable to a single factor. This variable is one-dimensional. Utilitarian criteria are represented by four items only.

This scale variable utilitarian criterion has a good level of reliability (Cronbach's $\alpha=0.803$ is close to 1): The scale has good internal consistency. The covariance between the items is high.

\subsection{The variable peripheral services}

After a first PCA, we found Cronbach's alpha equal to 0.814 and commonality following three items below 0.5 (activities for children, free bags, gifts and discounts).

We repeated the PCA with the four items remaining after the removal of the three items above. The result of the second PCA gave a Cronbach's alpha of 0.746 and another item (presence of DAB) with communality below 0.5 . A third PCA is required then the results are as follows:

\begin{tabular}{|l|l|l|}
\hline Items & Commonality & Component \\
\hline "The service seemed quite sure to you" & 0,711 & 0,843 \\
\hline "Many services were supplied on the raw (possibility to order, ...)" & 0,73 & 0,854 \\
\hline "It was possible to obtain free gift wrap" & 0,564 & 0,751 \\
\hline KMO measure of sampling & \multicolumn{2}{|c|}{0,666} \\
\hline Bartlett's test of sphericity: Chi-square approached & \multicolumn{2}{|c|}{192,833} \\
\hline Bartlett's test of sphericity: dll & \multicolumn{2}{|c|}{0} \\
\hline Bartlett's test of sphericity: meaning & 0 \\
\hline
\end{tabular}

Structure indicators appear significant (but KMO is average). These items are correlated to the dimension. All these items are factorable to a single factor. This variable is one-dimensional. Peripheral services are represented by three items only.

This scale variable peripheral services has a good level of reliability (Cronbach's $\alpha=0.747$ is close to 1): The scale has good internal consistency. The covariance between the items is high.

\subsection{The atmosphere variable}

After a first PCA, we found Cronbach's alpha equal to 0.912 and the commonality of the two following items below 0.5 (the waiting times and the mall).

We redid the PCA with seven items remaining after the removal of the two previous items. The result of the second PCA gave a Cronbach's alpha of 0.917 and another item (nice music) with communality less than 0.5. A third PCA is required then the results are as follows:

\begin{tabular}{|l|l|l|}
\hline \multicolumn{1}{|c|}{ Items Component } \\
\hline $\begin{array}{l}\text { "The supermarket/hypermarket (ground beams, crates) } \\
\text { was clean" }\end{array}$ & 0,752 & 0,869 \\
\hline $\begin{array}{l}\text { "The temperature of the supermarket/hypermarket was } \\
\text { nice" }\end{array}$ & 0,78 & 0,883 \\
\hline "The interior was pleasant" & 0,731 & 0,855 \\
\hline $\begin{array}{l}\text { "The outside of the supermarkets and hypermarkets (front, } \\
\text { sign, landscaping) was fun" }\end{array}$ & 0,592 & 0,769 \\
\hline $\begin{array}{l}\text { "The smell in the supermarkets and hypermarkets was } \\
\text { pleasant" }\end{array}$ & 0,831 & 0,911 \\
\hline "The color scheme was nice" & 0,653 & 0,808 \\
\hline KMO measure of sampling & & 0,877 \\
\hline Bartlett's test of sphericity: Chi-square approached & & 1270,026 \\
\hline Bartlett's test of sphericity: dll & & 0 \\
\hline Bartlett's test of sphericity: meaning & & 15 \\
\hline
\end{tabular}

Structure indicators appear significant (but KMO is average). These items are correlated to the dimension. All these items are factorable to a single factor. This variable is one-dimensional. Peripheral services are represented by six items only.

This scale atmosphere variable has a good level of reliability (Cronbach's $\alpha=0.922$ is close to 1 ): The scale has good internal consistency. The covariance between the items is high.

\subsection{The satisfaction variable}

After a first PCA, we found Cronbach's alpha equal to 0.767 and the commonality of the four following items below 0.5 (the recommendation, satisfaction, habit and repetition).

We repeated the PCA with the two items remaining after the removal of the four previous items. The results of the second PCA were as follows: 
Attendance of Tunisian supermarkets and hypermarkets

\begin{tabular}{|l|l|l|}
\hline Items & Commonality & Component \\
\hline $\begin{array}{l}\text { Do you intend to continue to patronize your main supermarkets and } \\
\text { hypermarkets? }\end{array}$ & 0,74 & 0,86 \\
\hline $\begin{array}{l}\text { "Compared to other supermarkets and hypermarkets that you know, } \\
\text { it is:" }\end{array}$ & 0,74 & 0,86 \\
\hline KMO measure of sampling & & 0,5 \\
\hline Bartlett's test of sphericity: Chi-square approached & & 67,409 \\
\hline Bartlett's test of sphericity: dll & & 1 \\
\hline Bartlett's test of sphericity: meaning & & 0 \\
\hline
\end{tabular}

The commonality of items is greater than 0.7. The components of items are greater than 0.8. The KMO is 0.5 . The test of Bartlett's sphericity gives an approached chi-square of 67.409 with zero significations. The indicators of structure appear acceptable. These items are correlated to the dimension. All these items are factorable to a single factor. This variable is one-dimensional. Satisfaction is represented by two items: the intention and comparing. Alpha of Cronbach = 0.6.

\subsection{The access variable:}

After a first PCA, we found Cronbach's alpha equal to 0.745 and the commonality of the two following items below 0.5 (the crowd and the cost of parking).

We redid the PCA with seven items remaining after the removal of the two previous items. The result of the second PCA gave a Cronbach's alpha of 0.884 and another item (journey time) with a communality less than 0.5 .

A third PCA is then required, the results are as follows:

\begin{tabular}{|l|l|l|}
\hline Items & Commonality & Component \\
\hline "This supermarket/hypermarket is very well located for me" & 0,643 & 0,802 \\
\hline "There is no risk during the trip" & 0,612 & 0,783 \\
\hline "The trip is tiring to come" & 0,753 & 0,868 \\
\hline "The trip has a cost" & 0,686 & 0,828 \\
\hline "It is tiring to find a place in the parking" & 0,536 & 0,732 \\
\hline "You lose a lot of time to find a place in parking" & 0,519 & 0,72 \\
\hline KMO measure of sampling & & 0,869 \\
\hline Bartlett's test of sphericity: Chi-square approached & & 763,599 \\
\hline Bartlett's test of sphericity: dll & & 15 \\
\hline Bartlett's test of sphericity: meaning & & 0 \\
\hline
\end{tabular}

Commonality of items is greater than 0.5. The components of items are greater than 0.7. The KMO is 0.869. The test of Bartlett's sphericity gives an approached chi-square of 763.599 with zero signification. The indicators of structure appear acceptable. These items are correlated to the dimension. All these items are factorable to a single factor. This variable is unidimensional. Access is represented by six items. This scale of the access variable has a good level of reliability (alpha of Cronbach $=0.877$ is close to 1 ). The scale has good internal consistency. The covariance between the items is high.

\section{The methods of data's analysis}

We chose the descriptive method because we try to describe the relationship between satisfaction and logistics, on the hand, and that between attendance and its determinants, on the other hand. We chose the techniques of linear and logistics regressions showing the impact of exogenous variables on the endogenous variable.

$\neg$ Simple linear regression: Simple linear regression describes a relationship between an exogenous quantitative variable (logistics) and an endogenous quantitative variable (satisfaction).

$\neg$ Logistics regression: Logistics regression is a non-linear regression used in the case of qualitative dependent variable (attendance is ordinal). With this regression, we will explain the "attendance" by the two quantitative variables following: "access" and "satisfaction."

Throughout this section we have tried to present the eight variables we proceed to analyze in our conceptual model: the five determinants of satisfaction ("environment", "price "," utilitarian criteria"," peripheral services "and "atmosphere") and two determinants of the supermarkets and hypermarkets attendance (" satisfaction "and" access").

To answer our question, we proceeded a survey through a quiz administered directly and individually to a convenient 260 customers sample interviewed out of six different supermarkets and hypermarkets (Carrefour, Geant, Carrefour Market, Monoprix, and Magasin Général Magro ).

It remains then to present, analyze and interpret the different results in the next section. 


\section{THE DETERMINANT OF SATISFACTION AND THE DETERMINANTS OF ATTENDANCE}

In our problematic, we will aim to find the impact of the determinants of satisfaction on customer satisfaction and the impact of satisfaction and access on supermarkets and hypermarkets attendance to determine the most important factors.

In this section, we address through a descriptive analysis of simple linear regressions describing the relationship between satisfaction with its determinants, and another logistic regression describing the relationship between attendance with its determinants. Through these two analysis methods, we will reach the validation or not of the research hypotheses.

\section{The determinant of satisfaction}

Determinants of satisfaction require the use of five simple linear regressions used to analyze the relationship between variables.

Quantitative explanatory variables are: environment, price, utilitarian criteria, peripheral services and atmosphere. The quantitative dependent variable is satisfaction.

\section{- The environment:}

Using a simple linear regression for two variables "environment" and "satisfaction", the unstandardized coefficient B is positive and equal to 0.43 . The relationship between the "environment" and "satisfaction" is significant. The signification is zero.

\section{- The price:}

Using a simple linear regression for two variables "price" and "satisfaction", the un-standardized coefficient B is positive and equal to 0.419 . The relationship between the "price" and "satisfaction" is significant. The signification is zero.

\section{- The utilitarian criteria:}

Using a simple linear regression for two variables "utilitarian criteria" and "satisfaction", the un-standardized coefficient B is positive and equal to 0.38 . The relationship between the "utilitarian criteria" and "satisfaction" is significant. The signification is zero.

\section{- The peripheral services:}

Using a simple linear regression for two variables "peripheral services" and "satisfaction", the un-standardized coefficient B is positive and equal to 0.344 . The relationship between the "peripheral services" and "satisfaction" is significant. The signification is zero.

\section{- The atmosphere:}

Using a simple linear regression for two variables "atmosphere" and "satisfaction", the un-standardized coefficient B is positive and equal to 0.402. The relationship between the "atmosphere" and "satisfaction" is significant. The signification is zero.

Recapitulation: The coefficients B of the explanatory variables are shown in the following table:

\begin{tabular}{|l|l|l|}
\hline Variables & The B- index & Meaning \\
\hline Environment & 0,43 & 0 \\
\hline Price & 0,419 & 0 \\
\hline Atmosphere & 0,402 & 0 \\
\hline Utilitarian criteria & 0,383 & 0 \\
\hline Peripheral services & 0,344 & 0 \\
\hline
\end{tabular}

"Environment", "price", "atmosphere", "utilitarian criteria" and "peripheral services" have a positive, significant and considerable satisfaction. The "environment", "price" and "atmosphere" have the greatest impact on satisfaction, in decreasing order.

To conclude, all the relations of satisfaction with its determinants are validated because the significance of Bartlett's test of sphericity is zero.

Once we tried the simple linear regressions of variables determining satisfaction, we must return to our research hypothesis.

Hypothesis Testing:

- Hypothesis 1 is confirmed: "The environment" supplied by the supermarkets and hypermarkets has a positive impact on satisfaction.

- Hypothesis 2 is confirmed: "The price" has a positive impact on satisfaction. 
- Hypothesis 3 is confirmed: "The utilitarian criteria" have a positive impact on satisfaction.

- Hypothesis 4 is confirmed: "The atmosphere" has a positive impact on satisfaction.

- The hypothesis is validated five "peripheral services" have a positive impact on satisfaction.

Regarding the first section of the model: the relationship between satisfactions with its determinants, we led to the validation of all hypothesis.

We turn now to the second section of the model: the relationship between "attendance" of supermarkets and hypermarkets with its determinants, to validate the hypothesis. To do so, we will use a logistic regression.

\section{The determinants of attendance}

To determine the relationship between attendance and its determinants, we used logistic regression on "access", "satisfaction" and "attendance". The relationship is, on the whole, significant with zero significations.

Only the "access" variable is significant (the significance is zero) and has a positive impact on attendance of supermarkets and hypermarkets. More the level of accessibility is higher, more the level of attendance is higher; that is to say, more the customer is near the supermarkets and hypermarkets, more he frequent it.

"Satisfaction" of customers has no significant impact on "attendance" because its signification is far greater than 0.005 (or 0.705). Tunisian customer doesn't attend the supermarkets and hypermarkets which he is the most satisfied with. So, because he is lazy, he doesn't get away frequently to make purchases. It can, for example, attend several times a week the supermarkets and hypermarkets nearest you and attend once a month another supermarkets and hypermarkets later.

The estimates of parameter give us the following results:

For first three levels of attendance (once every month, once every 3 weeks, and once per 15 days), the relationship between the "access" variable and the "attendance" variable is significant (significance of "access" variable is zero on the whole and the individual). Customers frequent supermarkets and hypermarkets more than once per 15 days depending on "access".

- $\quad$ For the latest level of attendance: "once a week", the relationship between all this variables is generally significant (signification $=0.01$ ) but not individually for the "access" variable (signification $=0.929$ ). Hypothesis Testing:

- $\quad$ The hypothesis 6a isn't validated: "satisfaction" toward a supermarkets and hypermarkets hasn't positive impact on attendance of supermarkets and hypermarkets.

- $\quad$ The hypothesis $6 \mathrm{~b}$ is validated: "access" has a positive impact on the level of supermarkets and hypermarkets's attendance by a customer.

\section{Recapitulation of results}

\section{CONCLUSION}

\section{Our model is divided into two sections:}

The first section of the model describes the relationship between "satisfaction" and its determinants. We used simple linear regressions, since all variables are quantitative: "satisfaction" (endogenous to explain) and its determinants (exogenous explanatory). This section of the model is validated. All the theoretical determinants of "satisfaction" are proven empirically. "Environment", "price", "atmosphere", "utilitarian criteria" and "peripheral services" have a positive impact on "satisfaction", as the first three determinants have the most important impact. For Tunisian customer of supermarkets and hypermarkets, the environment occur the most in satisfaction, and the peripheral services occurs the least on satisfaction.

For the second section of the model for "attendance" and its determinants, we used logistic regression because we want to explain a qualitative endogenous variable ("attendance" of supermarkets and hypermarkets) with two quantitative variables ("satisfaction" and "access"). One hypothesis on two has been validated. In other words, "access" has a positive impact on "attendance" of supermarkets and hypermarkets by customers: It is the only determinant of "attendance". A high level of attendance is the result of a higher level of access. Tunisian customer does not attend the supermarket/hypermarket which he is most satisfied but the closest. In fact, "Satisfaction" hasn't significant positive impact on attendance. Customers choose the nearest supermarkets and hypermarkets to them, which isn't the case for the foreign customer who also takes into account the "satisfaction" in his choice. This difference may be due to the different psychological, cultural and environmental contexts that may act differently on the Tunisian and foreign customers.

\section{Recommendations}

In this section, we will look at two different types of recommendations that complement each other: theoretical and managerial. 


\subsection{The theoretical recommendations}

All the theoretical determinants of "satisfaction" have been proven in our results. Except that the determinants of "attendance" have been partially proved.

The complexity of measurement of customers "satisfaction" is difficult and requires great care. It depends on several factors. Since, it is relative and subjective; it depends on the characteristics and cultural variables of customers. Same for "attendance" of supermarket/hypermarket.

The model analyzed in this work has been validated in Europe. The difference between our results and our research hypotheses is explained by cultural specificities observed between Tunisian and foreign customers.

Therefore, the researcher must be careful in the application of model in a culturally different. He should not be surprised at the different results obtained some of its hypothesis.

\subsection{Managerial recommendations} retailer.

The recommendations are two types: on the side of the supermarket/hypermarket and on the side of mix-

- The supermarket/hypermarket should address all the determinants of "satisfaction" variables especially "environment supplied by the supermarkets and hypermarkets," the "price" and "atmosphere" that have a strong relationship with "the satisfaction ". Retailer may, therefore, play on architecture, prestige, security, animation, price and atmosphere of the supermarkets and hypermarkets.

The retailer can also play on his proximity to customers in order to improve the attendance of their supermarkets and hypermarkets. Hence, comes the choice of their location.

- The mix-retailer: The retailer can play on different criteria of the mix such as:

The price to what customers are very sensitive. Lower prices always attract customers.

The place of sale shall be selected as close as possible to customers. The retailer must be established everywhere to ensure maximum attendance.

Communication through promotions and gifts supplies improve customer satisfaction.

\section{ACKNOWLEDGMENT}

We want to thank all those who helped us in this work, and especially managers of supermarkets and hypermarkets who allowed us to do our research in their supermarkets.

\section{REFERENCES}

Journal Papers :

[1]. Lichtlé Marie-Christine, Llosa Sylvie, Plichon Véronique. La contribution des différents éléments d'une grande surface alimentaire à la satisfaction du client, Recherche et Application en Marketing. Vol. 17, $n^{\circ} 4 / 2002$. Pg. 23, 12 pgs.

[2]. Léo Pierre-Yves, Philippe Jean. Positionnement concurrentiel des zones commerciales et satisfaction du consommateur. Recherche et Application en Marketing. Vol. 18, $n^{\circ} 3 / 2003$. Pg. 45, 19 pgs.

[3]. Huff, David L. (1964), Defining and estimating a trading area, Journal of Marketing, 39, 34-38.

[4]. Rulence David. Gestion des réseaux de points de vente : l'importance de la dimension spatiale. Recherche et application en marketing. Vol. $18, n^{\circ} 3 / 2003$. Pg. 65, 16 pgs.

[5]. Negro Y. (1985), Le positionnement : une arme pour le petit commerce spécialisé, Revue Française de Marketing, $n^{\circ}$ 103/3.

[6]. Volle P. (2000), Du marketing des points de ventes à celui des sites marchands : spécificités, opportunités et questions de recherche, Revue Française de Marketing, 177/178, 83-100.

[7]. Jones T. O. et Sasser W. E., (1995), Why satisfied customers defect, Harvard Business Review, 73, 6, 88-99.

[8]. Westbrook R. A. (1987), Product/Consumption-based affective responses and post purchase processes, Journal of Marketing Research, 24, 3, 258-270.

[9]. Tauber T. (1972), Why do people shop? Journal of Marketing, 36, 4, 46-59.

[10]. Roussel, P., Durrieu, F., Campoy, E., El Akremi, A., (2002), Méthodes d'équation struturelles : recherche et application en Gestion, Paris, Economica.

Books :

[1]. Debabi M. et all., Marketing de distribution et d'exportation. Ccoordonné par Debabi M. Lajili M. R et Mejri M. Préface de Fady A. Edition l'univers du livre 2007.

[2]. Amine A., Cadenat S. (2000), Etude et recherche sur la distribution. Economica.

[3]. Aurifeille J.-M. et Quester P.-G., (2000), globalisation ou internationalisation: une méthode d'analyse fondée sur les profils d'implication. Faire de la recherche en logistique et distribution ?, éds N. Fabbe-Costes, J. Colin et G. Paché, Paris, Vuilbert FEGE, 231-249.

[4]. Tordjman A. (1992), L'Europe du commerce : convergences et perspectives. Etudes et Recherches. NEGOCIA. Paris.

[5]. Rieunier S. (2002), Le marketing sensorielle des points de vente : créer et gérer l'ambiance des lieux commerciaux. Edition Dunod.

[6]. Jallais J., Orsoni J. et Fady A. (1994), Le marketing dans le commerce de détail. Paris Vuibert.

Theses:

[1]. Llosa S. (1996), Contribution à l'étude de la satisfaction dans les services, Thèse de doctorat en sciences de gestion, Université de Droit, d'Economie et des Sciences d'Aix-Marseille.

[2]. Meziou, R., (2010), L'impact du parrainage télévisuel sur les réponses des consommateurs : rôle de la congruence entre une émission et un parrain, thèse de doctorat en science de gestion (en cotutelle), Faculté des sciences économiques et de gestion de Tunis et l’Université Jean Moulin Lyon 3.

Proceedings Papers:

[1]. Reimer V. et Clulow V. (2001), downtown shopping: is it worth time and effort ?, Actes de la conférence international sur le management des services, éd. Largo, Université d'Angers, 363-372. 